\title{
Carbon Dioxide Capture and Storage
}

\author{
Sally M. Benson (Stanford University, USA) and Franklin M. Orr, Jr. (Stanford University, USA)
}

Reducing $\mathrm{CO}_{2}$ emissions from the use of fossil fuel is the primary purpose of carbon dioxide capture and storage (CCS). Two basic approaches to CCS are available. ${ }^{1,2}$ In one approach, $\mathrm{CO}_{2}$ is captured directly from the industrial source, concentrated into a nearly pure form, and then pumped deep underground for long-term storage (see Figure 1). As an alternative to storage in underground geological formations, it has also been suggested that $\mathrm{CO}_{2}$ could be stored in the ocean. This could be done either by dissolving it in the mid-depth ocean $(1-3 \mathrm{~km})$ or by forming pools of $\mathrm{CO}_{2}$ on the sea bottom where the ocean is deeper than $3 \mathrm{~km}$ and, consequently, $\mathrm{CO}_{2}$ is denser than seawater. The second approach to $\mathrm{CCS}$ captures $\mathrm{CO}_{2}$ directly from the atmosphere by enhancing natural biological processes that sequester $\mathrm{CO}_{2}$ in plants, soils, and marine sediments. All of these options for CCS have been investigated over the past decade, their potential to mitigate $\mathrm{CO}_{2}$ emissions has been evaluated, ${ }^{1}$ and several summaries are available. ${ }^{1,3,4}$

With over $60 \%$ of worldwide $\mathrm{CO}_{2}$ emissions coming from point sources that are potentially amenable to $\mathrm{CO}_{2}$ capture and a minimum of $2,000 \mathrm{Gt}$ (billion metric tonnes) of storage capacity in deep geological formations, the prospects for CCS to make a large contribution to reducing $\mathrm{CO}_{2}$ emissions are great. ${ }^{1}$ Technical and economic assessments suggest that, over the coming century, CCS could contribute up to $20 \%$ of needed $\mathrm{CO}_{2}$ emission reductions, on par with expected reductions from efficiency improvements and large-scale deployment of renewable energy resources. ${ }^{5}$
Scientists and engineers are working both to lower costs and to increase the efficiency of post-combustion capture. Research opportunities include more efficient and robust chemical solvents and membranes for separating $\mathrm{CO}_{2}$ from $\mathrm{N}_{2}$, as well as materials to reduce capital costs of the large separation vessels and contactors needed for industrial-scale capture. New materials that can withstand higher temperatures and pressures could also improve the efficiency of power generation with $\mathrm{CO}_{2}$ capture.

Pre-combustion capture might offer lower costs and higher efficiency. Here, the fossil fuel is first gasified to produce syngas, a mixture of $\mathrm{H}_{2}$ and $\mathrm{CO}$. In the process of gasification, a nearly pure stream of $\mathrm{CO}_{2}$ is produced. If all of the $\mathrm{CO}$ is further converted to $\mathrm{CO}_{2}$ by the water-gas shift reaction, a pure stream of hydrogen is produced that emits only water after combustion. Gasification is a well-established technology in the chemical manufacturing and refining industries, but there is only limited experience with gasification combined with power generation. A number of projects to demonstrate electricity production with pre-combustion capture are underway today, using a technology called integrated gasification combined cycle (IGCC). Cost for pre-combustion $\mathrm{CO}_{2}$ capture are estimated to be about $\$ 20$ per tonne, ${ }^{3}$ but more experience is needed to establish reliable estimates. ${ }^{1}$ The third approach, often called oxycombustion, burns fossil fuels in a pure oxygen environment instead of air to avoid the need to separate $\mathrm{CO}_{2}$ from $\mathrm{N}_{2}$ in the exhaust gas, which instead consists of a mixture of $\mathrm{CO}_{2}$ and water. Oxycombustion offers the benefit that retrofits of existing

\section{Carbon Dioxide Capture from Industrial Sources}

Carbon dioxide can be captured directly from industrial sources by one of three methods: post-combustion capture, precombustion capture, or combustion of fossil fuels in a pure oxygen environment. A schematic illustrating these approaches is shown in Figure 2. Post-combustion capture separates $\mathrm{CO}_{2}$ from exhaust gas, which consists primarily of a mixture of $\mathrm{N}_{2}$ and $\mathrm{CO}_{2}$, using chemical solvents such as monoethanolamine. The advantage of post-combustion capture is that existing industrial facilities and power plants could be retrofitted for $\mathrm{CO}_{2}$ capture. However, with today's technology, at a cost of about $\$ 40$ per tonne of $\mathrm{CO}_{2}$ avoided ${ }^{3}$ and an efficiency reduction of $25 \%,{ }^{3}$ incentives to reduce greenhouse gas emissions will be needed before large-scale deployment occurs.

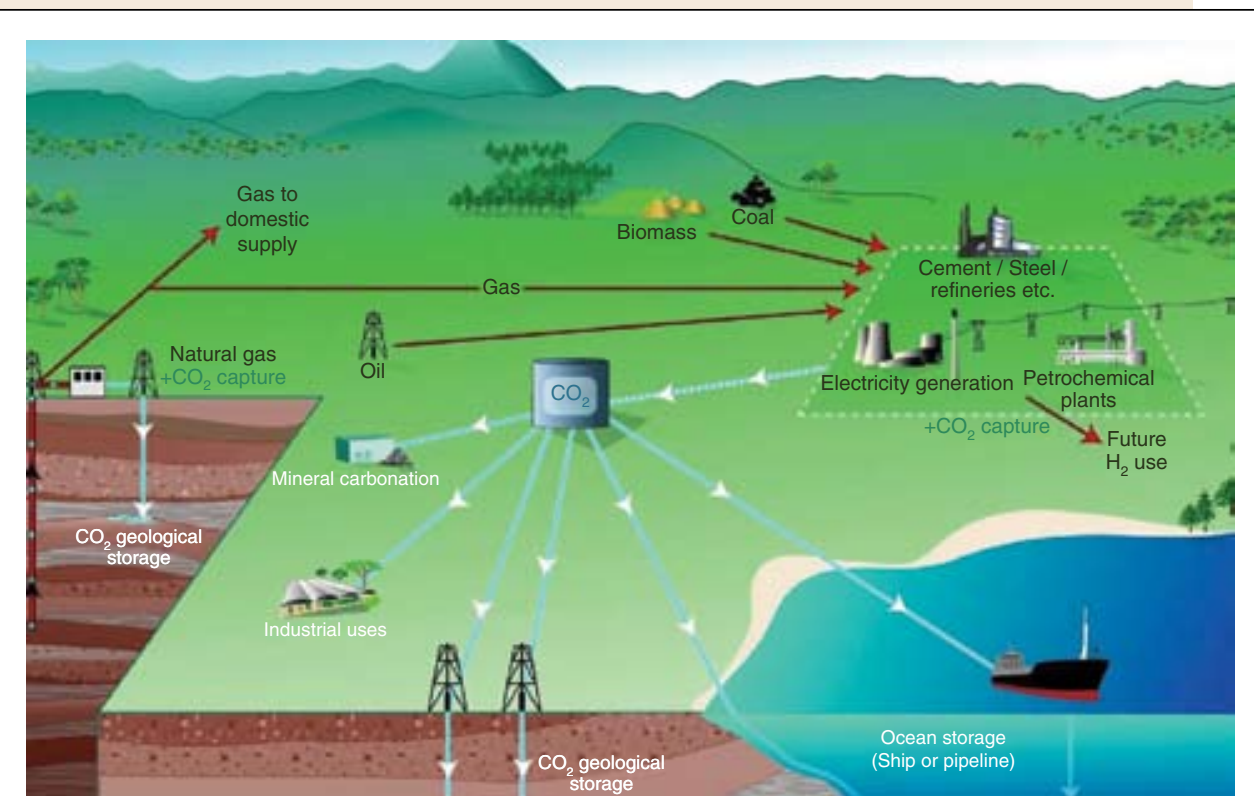

Figure 1. Schematic showing carbon dioxide capture from industrial sources and storage in either deep geological formations or the deep ocean (from Reference 1). 
Overview of $\mathrm{CO}_{2}$ capture processes and systems

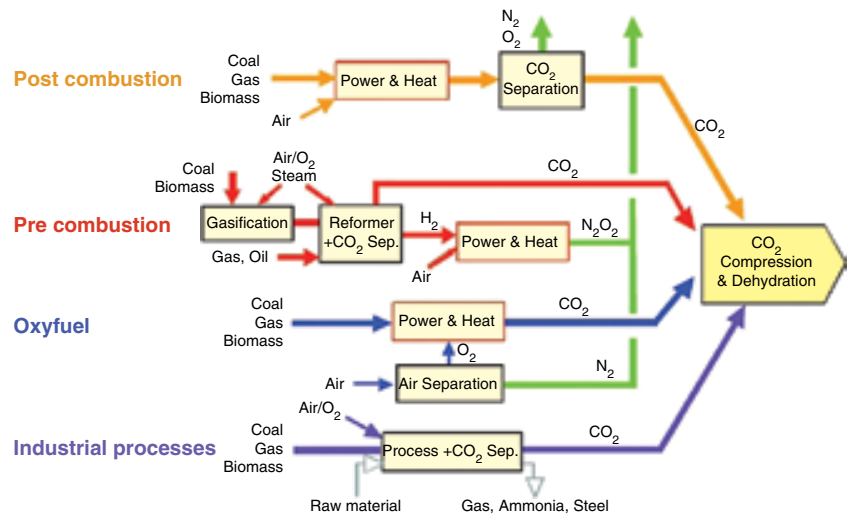

Figure 2. Illustration showing different approaches for capturing carbon dioxide from industrial sources (from Reference 1). provide the seals above the storage reservoir that can trap buoyant fluids such as oil, natural gas, and $\mathrm{CO}_{2}$ for millions of years. Because $\mathrm{CO}_{2}$ has a lower density than water, the presence of an overlying, thick, and continuous layer of silt, clay, or evaporite is the single-most important feature of a geologic formation that is suitable for geological storage of $\mathrm{CO}_{2}$. These fine-textured rocks physically prevent the upward migration of $\mathrm{CO}_{2}$ by a combination of viscous and capillary forces.

One of the key questions for geologic storage is: how long will the $\mathrm{CO}_{2}$ remain trapped underground? Based on a number of lines of evidence, experts have concluded that retention rates of greater than $99 \%$ over 1000 years are likely for well-selected and -managed geological storage reservoirs. ${ }^{1}$ Support for this conclusion stems from the fact that natural oil, gas, and $\mathrm{CO}_{2}$ reservoirs have trapped buoyant fluids such as $\mathrm{CO}_{2}$ underground for millions of years, as well as from practical experience injecting and storing gases underground for natural gas storage, $\mathrm{CO}_{2}-$ enhanced oil recovery (EOR), and acid gas disposal. In addition, multiple physical and chemical processes contribute to longterm retention of $\mathrm{CO}_{2}$, including dissolution of $\mathrm{CO}_{2}$ in brine,

facilities might also be possible. However, experience with this technology is limited, and achieving the high potential efficiency of oxycombustion will require advanced materials and operating environments that can handle the higher temperatures required. Extensive research and development (R\&D) and several demonstration projects are underway to assess the potential for oxycombustion with $\mathrm{CO}_{2}$ capture. Materials research opportunities for IGCC and oxycombustion are similar to those for post-combustion capture, but for IGCC, membranes that separate $\mathrm{H}_{2}$ from $\mathrm{CO}_{2}$ are needed.

After the $\mathrm{CO}_{2}$ is separated, it must be compressed to a pressure of about 100 bar into a liquid state and transported through pipeline or ship to the storage location. Compression and transportation of $\mathrm{CO}_{2}$ is done routinely today.

\section{Carbon Dioxide Storage in Deep Geological Formations}

Once the $\mathrm{CO}_{2}$ is captured, as shown in Figure 3, it can be pumped down wells into deep underground formations such as depleted oil and gas reservoirs, brine-filled formations, or deep unmineable coal beds. These types of formations occur in basins filled with sedimentary rocks that can accumulate up to thousands of meters of sediment. The pore spaces in these sedimentary rocks are filled with salt water or, in some cases, oil and gas. The rocks in sedimentary basins consist of alternating layers of sand, silt, clay, carbonate, and evaporites that were long ago deposited in oceans, deltas, lakes, and rivers. The sand layers provide storage space. The silt, clay, and evaporite layers capillary trapping of $\mathrm{CO}_{2}$, adsorption on coal, and mineral trapping; together, these trapping mechanisms increase the security of storage over time, thus further diminishing the possibility of potential leakage and surface release. Over hundreds to thousands of years, the majority of $\mathrm{CO}_{2}$ is expected to be immobilized through one or more of these trapping mechanisms.

The technology for storing $\mathrm{CO}_{2}$ in deep underground formations is adapted from oil and gas exploration and production technology. For example, technologies to drill and monitor wells that can safely inject $\mathrm{CO}_{2}$ into the storage formation are available. Methods to characterize a site are fairly well devel- 
oped, although much more experience is needed to reliably assess seals and the storage capacity of saline aquifers. Models are available to predict where $\mathrm{CO}_{2}$ will move when it is pumped underground, although more work is needed to develop and test these models further. Monitoring of the subsurface movement of $\mathrm{CO}_{2}$ is currently being successfully conducted at several sites, although again, more work is needed to refine and test monitoring methods. The health, safety, and environmental risks associated with geological storage are comparable to the nature and magnitude of the risks associated with analogous activities such as natural gas storage, enhanced oil recovery, and acid gas injection. ${ }^{1}$

Three industrial-scale CCS projects are operating today, a fourth was scheduled to start in late $2007,,^{6-8}$ and numerous other projects are in advanced stages of planning. The first of these projects, the Sleipner Saline Aquifer Storage Project, began 11 years ago. ${ }^{6}$ Annually, $1 \mathrm{Mt}$ (million metric tonnes) of $\mathrm{CO}_{2}$ are separated from natural gas and stored in a deep sub-sea brinefilled sandstone formation. ${ }^{5}$ The In Salah Gas Project in Algeria began in 2004 and is storing $1 \mathrm{Mt}$ of $\mathrm{CO}_{2}$ annually in the flanks of a depleting gas field. ${ }^{7}$ The third industrial-scale CCS project, located in Saskatchewan, Canada, uses $\mathrm{CO}_{2}$ from the Dakota Gasification Plant in North Dakota to simultaneously enhance oil production and store $\mathrm{CO}_{2}$ in the Weyburn Oil Field. ${ }^{8} \mathrm{~A}$ new $1000 \mathrm{MW}$ coal-fired power plant can emit about $6 \mathrm{Mt} \mathrm{CO}_{2}$ annually. ${ }^{3}$ These quantities are larger than the existing capture and storage projects, but experience suggests that capture and storage of this magnitude should be possible. However, the task of storing the billions of tonnes of $\mathrm{CO}_{2}$ generated annually from power production alone is daunting - and is likely to require an infrastructure on the scale of today's oil and gas infrastructure.

Materials research into more durable and corrosion-resistant cements, self-sealing and self-healing well-completion materials, and lower-cost corrosion-resistant pipe for injection wells would be beneficial. In addition, nondestructive methods for in situ characterization of the condition of pipes, cement, and other well-sealing materials could improve methods for monitoring the condition of wells.

\section{Carbon Dioxide Storage in the Ocean}

Storing captured $\mathrm{CO}_{2}$ in the ocean has also been proposed. Compressed $\mathrm{CO}_{2}$ would be transported by pipeline or ship and then pumped into the deep ocean. The $\mathrm{CO}_{2}$ could be injected through a diffuser to accelerate dissolution into the water column, or alternatively, it could be pumped into "lakes" on the sea bottom. At depths below about $350 \mathrm{~m}, \mathrm{CO}_{2}$ forms a solid clathrate that is denser than seawater, but then dissolves relatively rapidly in the surrounding seawater. ${ }^{9}$ Sea-bottom storage requires water column depths of at least $3 \mathrm{~km}$ to ensure that $\mathrm{CO}_{2}$ is denser than the ocean water; otherwise, the $\mathrm{CO}_{2}$ would rise through the water column and return quickly to the atmo- sphere. Over hundreds to thousands of years, some fraction of the $\mathrm{CO}_{2}$ stored in the ocean would return to the atmosphere as a result of circulation in the ocean. Concern over biological impacts and negative public opinion about ocean storage have curtailed interest and R\&D in this area. ${ }^{1}$ As an alternative to direct injection in the water column, a new approach to seabottom storage involving injection under the sea-bottom sediments that would overcome many of the concerns described here has been proposed, ${ }^{10}$ although this option is in the early stages of R\&D.

\section{Cost of $\mathrm{CO}_{2}$ Capture and Storage}

Estimated additional costs for generating electricity from a coal-fired power plant with CCS range from \$20 to \$70/tonne of $\mathrm{CO}_{2}$ avoided, depending mainly on the capture technology and concentration of $\mathrm{CO}_{2}$ in the stream from which it is captured. ${ }^{1}$ At these rates, electricity-generating costs would increase from $50 \%$ to $100 \%$ over those of plants with $\mathrm{CO}_{2}$ capture. ${ }^{1}$ Capture and compression typically account for over $75 \%$ of the costs of CCS, with the remaining costs attributed to transportation and underground storage. Pipeline transportation costs are highly site-specific, depending strongly on economies of scale and pipeline length. The R\&D efforts discussed are underway to reduce the cost of capture and compression, making widespread deployment of CCS more viable.

\section{References}

1. Intergovernmental Panel on Climate Change, Special Report on Carbon Dioxide Capture and Storage (Cambridge University Press, Cambridge, UK, 2005).

2. S.M. Benson, T. Surles, Proc. IEEE 94 (10), 1795 (2006).

3. The Future of Coal (Massachusetts Institute of Technology, Cambridge, MA, 2007).

4. Battelle, "Technology Report from the Second Phase of the Global Energy Technology Strategy Program" (2007).

5. "IPCC, 2007: Summary for Policymakers," in Climate Change 2007: Mitigation. Contribution of Working Group III to the Fourth Assessment Report of the Intergovernmental Panel on Climate Change, B. Metz, O.R. Davidson, P.R. Bosch, R. Dave, L.A. Meyer, Eds. (Cambridge University Press, Cambridge, UK, 2007).

6. T.A. Torp, J. Gale, in Proceedings of the 6th International Conference on Greenhouse Gas Control Technologies (GHGT-6), J. Gale, Y. Kaya, Eds., 1 (10) (Kyoto, Japan, Pergamon, Amsterdam, 2002), 311.

7. F.A. Riddiford, A. Tourqui, C.D. Bishop, B. Taylor, M. Smith, in Proceedings of the 6th International Conference on Greenhouse Gas Control Technologies (GHGT-6), J. Gale, Y. Kaya, Eds., 1 (10) (Kyoto, Japan, 4 Pergamon, Amsterdam, 2002), 601.

8. R. Moberg, D.B. Stewart, D. Stachniak, in Proceedings of the 6th International Conference on Greenhouse Gas Control Technologies (GHGT6), J. Gale, Y. Kaya, Eds., 1 (10) (Kyoto, Japan, 4 Pergamon, Amsterdam, 2002), 219.

9. P.G. Brewer, G. Friederich, E.T. Peltzer, F.M. Orr, Jr., Science 284, 943 (1999).

10. K.Z House, D.P. Schrag, C.F. Harvey, K.S. Lackner, Proc. Natl. Acad. Sci. 103 (33), 12291 (2006).

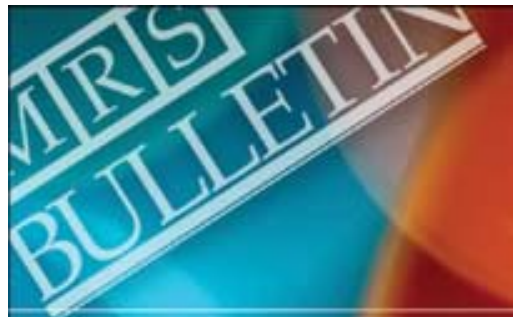

Don't miss this related MRS BULLETIN back issue! January 2008

Advancing Materials and Technologies for Water Purification Guest Editors: Mark A. Shannon and Raphael Semiat 


\section{Materials for Your Research}

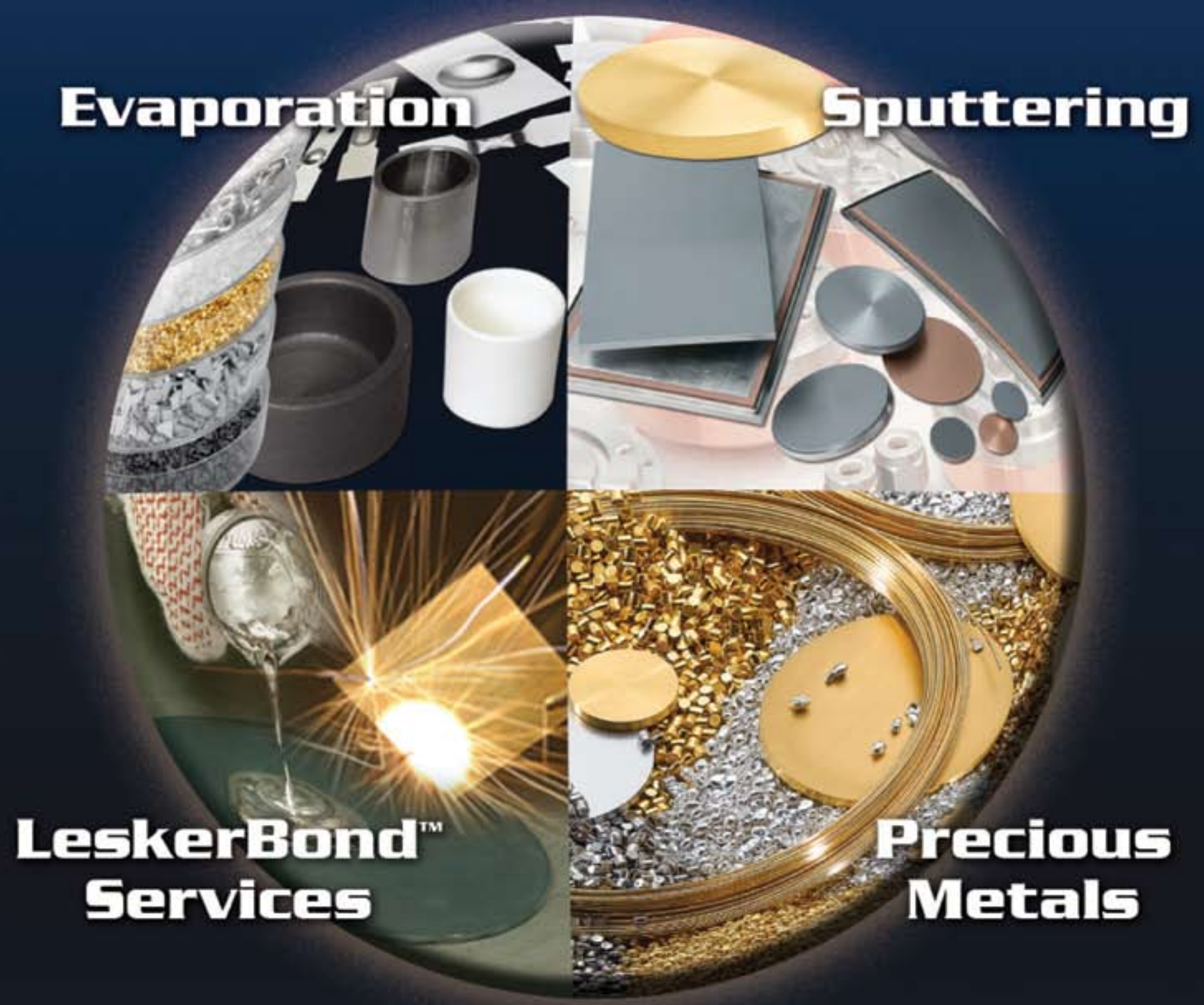

While the world's need for technology grows, so does the materials offering at Kurt J. Lesker Company. From R\&D to Production we have all your thin-film material needs covered. As a manufacturer of vacuum equipment for over 50 years, we have a true understanding of the importance of quality and availability. Being on the cutting edge isn't just our job. . . it's our responsibility.

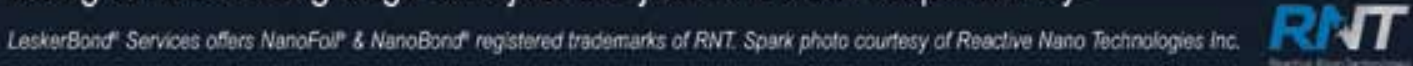

\section{For more information: www.lesker.com}

\section{Kurt J. Lesker}

